$\sqrt{2} \geqslant 191$ and

PPPL-2795

UC-426 (f)

PREPARED FOR THE U.S. DEPARTMENT OF ENERGY, UNDER CONTRACT DE-AC02-76-CHO-3073

PPPL-2795
THE INTERPRETATION OF REFLECTOMETRY MEASUREMENTS OF PLASMA FLUCTUATIONS

BY

N. BRETZ

October 1991
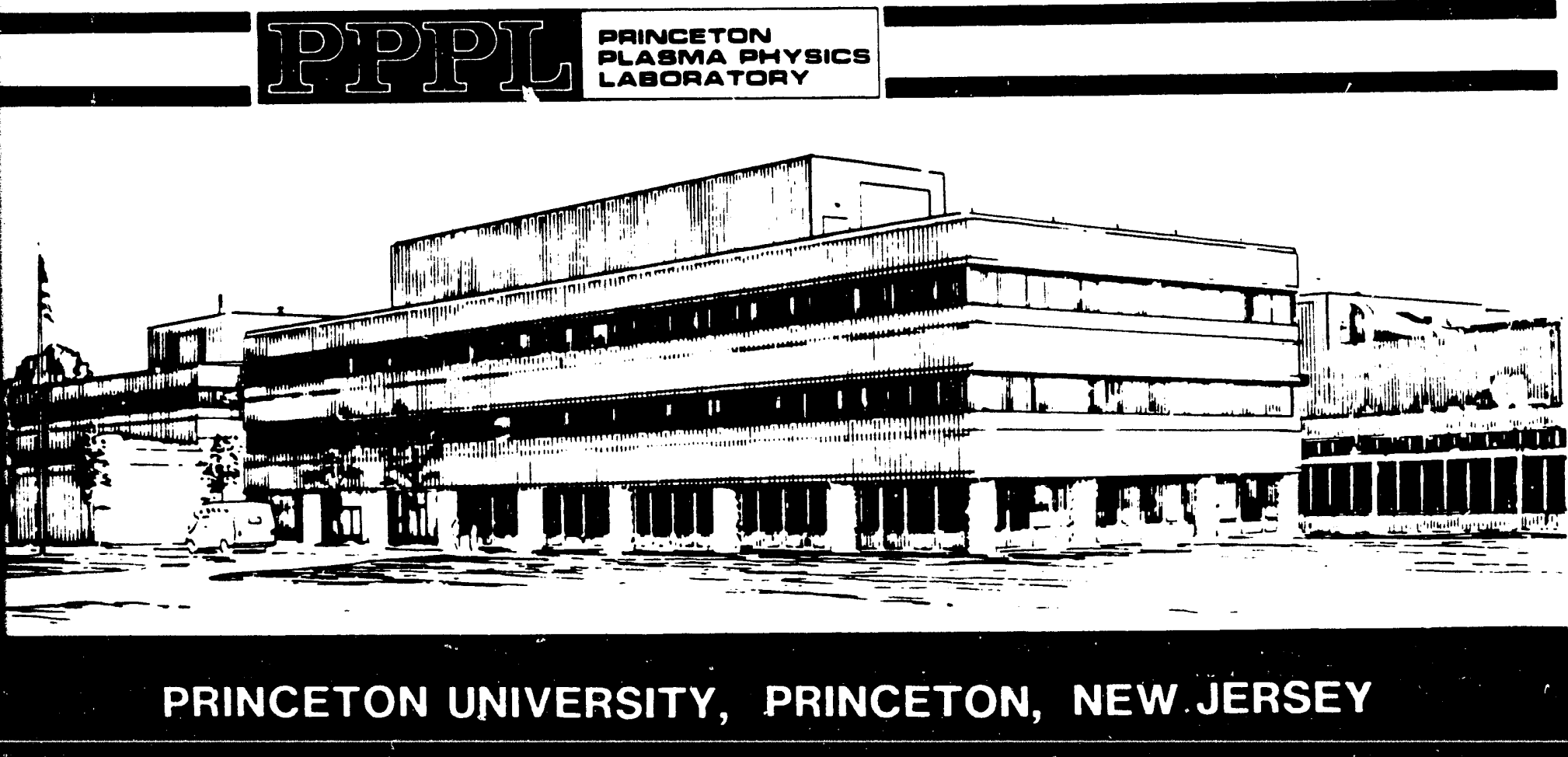


\section{NOTICE}

This report was prepared as an account of work sponsored by an agency of the United States Government. Neither the United States Government nor any agency thereof, nor any of their employees, makes any warranty, express or implied, or assumes any legal liability or responsibility for the accuracy, completeness, or usefulness of any information, apparatus, product, or process disclosed, or represents that its use would not infringe privately owned rights. Reference herein to any specific commercial produce, process, or service by trade name, trademark, manufacturer, or otherwise, does not necessarily constitute or imply its endorsement, recommendation, or favoring by the United States Government or any agency thereof. The views and opinions of authors expressed herein do not necessarily state or reflect those of the United States Government or any agency thereof.

\section{NOTICE}

This report has been reproduced directly from the best available copy.

Available to DOE and DOE contractors from the:

Office of Scientific and Technical Information

P.O. Box 62

Oak Ridge, TN 37831;

Prices available from (615) 576-8401.

Available to the public from the:

National Technical Information Service

U.S. Department of Commerce

5285 Port Royal Road

Springfield, Virginia 22161

$703-487-4650$ 


\title{
The Interpretation of Reflectometry Measurements of Plasma Fluctuations
}

\author{
by N. Bretz \\ Princeton Plasma Physics Laboratory \\ Princeton University \\ Princeton, NJ 08543
}

\begin{abstract}
Wave reflections from density fluctuations with magnitudes and frequencies typical of drift waves have been investigated. Both drift waves and the reflected phase and amplitude depend on the density gradient scale length, and this common feature implies that both the angular deviation of a normally propagating wave and the phase change on reflection are of order unity. Thus the surface will always appear "rough" and amplitude variations will always be large. For smaller amplitude waves numerical solutions of the one dimensional full wave equation for the propagation near cutoff frequencies has been used to show how to interpret reflectometry measurements. For density perturbations with wavelengths near the density scale length, the external fluctuating phase can be simply interpreted in terms of a fluctuating density near the ciitoff layer. However, the amplitude of the phase response falls substantially as the fluctuation wavelength, $\Lambda$, approaches the free space wavelength of the reflected wave, $\lambda_{0}$, and the location of the maximum response moves out in front of the cutoff layer following the wave matching condition $k_{\Lambda}=2 k \approx$ $2 \eta(x) k_{0}$. Similarly, correlation measurements of density fluctuations from probe waves of different wavelengths are shown to be limited to about four times the average reflected wavelength.
\end{abstract}

\section{MASTER}




\section{Introduction}

In order to measure plasma density fluctuations a number of researchers have reflected microwaves from a cutoff layer. Changes in the phase of the incident or probe wave compared to the reflected wave have been interpreted as fluctuations in the plasma density near the cutoff. ${ }^{1}$ The situation is complicated by the fact that the total phase change, $\delta \Phi$, is, in the WKB approximation, an integral quantity

$$
\delta \Phi_{w \mathrm{~kg}}\left(\mathrm{k}_{\mathrm{o}}\right) \approx 2 \mathrm{k}_{\mathrm{o}} \delta\left[\int_{0}^{\mathrm{x}_{c o}\left(\mathrm{k}_{\mathrm{o}}, \mathrm{n}_{\mathrm{e}}\right)} \eta\left[\mathrm{k}_{\mathrm{o}}, \mathrm{n}_{\mathrm{e}}(\mathrm{x})\right] \mathrm{dx}\right]
$$

whose value depends not only on the location of the cutoff, $x_{c o}$, and its change with electron density, $\mathrm{n}_{\mathrm{e}}$, but also on the integral over the plasma index, $\eta$, over the path of the probe wave. Here $\lambda_{0}=2 \pi / \mathrm{k}_{0}=c / \omega_{0}$ is the free space wavelength. The correct evaluation of the phase variation must be found by solving the full time independent wave equation and finding the phase change which results from a test density perturbation. In this paper numerical solutions will be found for several model situations in order to show how the magnitude of the phase changes as the location and the dominant wavelength of the perturbation are varied.

The effect of drift waves, which are thought to significantly affect the confinement in tokamaks, will be examined in some detail, but the analysis will apply equally well to any fluctuation whose frequency is much less than the probe wave. There is a relationship between reflectometry measurements and drift waves that originates in their common dependence on the density gradient scale length. This relationship puts a limit on what can be expected from such measurements: probe waves with wavelengths which are short compared to the dominant fluctuation wavelengths perpendicular to the propagation direction will be scattered at large angles and probe waves which are short compared to the dominant wavelength along the direction of propagation will have a phase change of order unity. That is, long wavelength drift waves near the cutoff layer will make the surface appear "rough" and the concept of a simple, 
mirror-like, reflection will break down.

In the case where the fluctuation amplitude perpendicular to the probe wave is sufficiently low or when the probe wavelength is sufficiently large compared to the plasma waves, a one dimensional model can be used. In this model the ratio of the phase to density fluctuations is strongly dependent on the perturbation wavelength. When the wavelength of the probe is near or less than the wavelength of the plasma wave, this ratio approaches zero and the fluctuations most responsible for the phase change occur well away from the reflection point. In the opposite limit, when the plasma wavelength is much longer than the probe wavelength, the change in phase depends primarily on changes in the location of the cutoff layer, and a simple formula can be given for the ratio. Both extraordinary waves and ordinary waves will be treated and found to give essentially similar results except for obvious differences in the cutoff wavelength and the parametric dependence of the cutoff location. The exact form of the density profile is never an important issue in the interpretation of fluctuations as long as the probe wavelength is much smaller than the density gradient scale length. However, the most significant parameter in determining the magnitude of the phase change is the density gradient scale length near cutoff.

Using the same one dimensional full wave model, limitations on correlation measurements are also examined. Correlations in probe waves with different wavelengths which reflect from different cutoff locations in the plasma can give information on the radial correlation length of density fluctuations. Model calculations show that correlation lengths inferred from phase measurements can never be less than about four times the free space wavelength of the probe wave. Any reflectometry measurements which infer correlation lengths which are as small as the probe wavelength must be influenced by features outside this model such as the two dimensional "rough" surface effect where amplitude and phase variations are large and where measurements of the spatial pattern of reflected intensity will be as important as the measurement of phase in reconstructing the structure of local density fluctuations. 
II. Reflection from drift waves

First, several estimates will be made of the type of phase change expected for drift waves. Drift waves typically have a frequency which is low compared to the characteristic electron cutoffs and resonances, and have a characteristic level of density fluctuations and dominant scale lengths which mark a natural division between reflectometry which is simple (that is, has phase changes less than unity and which is primarily a one dimensional problem) from the more complex situation where changes the angle of the reflecting surface significantly alters the direction of the reflected ray. We will only consider propagation approximately perpendicular to $\mathbf{B}$ and to the density gradient. Two simple situations will be discussed: 1) fluctuations perpendicular to the propagation direction, and 2) fluctuations parallel to the propagation direction.

Drift waves are driven by density gradients and for laboratory plasmas have characteristic frequencies much smaller than the probe wave frequency, $\omega_{0}$, the electron plasma frequency, $\omega_{\mathrm{pe}}$, or the electron cyclotron frequency, $\omega_{\mathrm{ce}}$. These waves consist of density perturbations propagating in the electron diamagnetic drift direction, $\nabla \mathbf{n} \times \mathbf{B}$, with a dispersion relation ${ }^{2}$

$$
\omega_{\mathrm{De}}{ }^{*}=\mathrm{k}_{\theta} \mathrm{v}_{\mathrm{De}} /\left(1+\mathrm{k}_{\theta}^{2} \rho_{\mathrm{s}}^{2}\right)
$$

where $\omega_{\mathrm{De}}{ }^{*}$ is called the electron diamagnetic drift frequency, the diamagnetic drift velocity is given by $v_{D e}=v_{T e}{ }^{2} / \omega_{c e} / L_{n}$ where $v_{T e}=$ $\left(\mathrm{T}_{\mathrm{e}} / \mathrm{m}_{\mathrm{e}}\right)^{1 / 2}, \mathrm{~L}_{\mathrm{n}}$ is the density scale length, $\mathrm{n}_{\mathrm{e}} /\left(\mathrm{d} \mathrm{n}_{\mathrm{e}} / \mathrm{dr}\right), \rho_{\mathrm{s}}=\mathrm{c}_{\mathrm{s}} / \omega_{\mathrm{ci}}, \mathrm{c}_{\mathrm{s}}=$ $\left(T_{e} / m_{i}\right)^{1 / 2}$, and $\omega_{c i}$ is the ion cyclotron frequency. In toroidal coordinates the density gradient is radial ( $r$ ) while the primary wave direction is poloidal $(\theta)$. For large tokamaks like JET, TFTR, or JT-60 these estimates give $\delta \mathrm{n}_{\mathrm{e}} / \mathrm{n}_{\mathrm{e}} \approx 0.1$ to $1.0 \%$ and $\omega_{\mathrm{De}}{ }^{*} / 2 \pi=20$ to $100 \mathrm{kHz}$ in the interior of the plasma.

In a sheared system like the tokamak these waves grow in the $r-\theta$ plane where the fluctuation spectrum tends to become symmetric. Wave growth is limited when the wave amplitude starts to flatten the density gradient, that is, when 


$$
\delta n_{e} / n_{e} \approx 1 /<k_{\theta, r} \chi_{n}
$$

The value of $\left\langle k_{\theta}\right\rangle$ has been estimated from several saturation models to give $\rho_{\mathrm{s}}\left\langle k_{\theta}\right\rangle \approx 0.2$ to 1.0. This level has been observed experimentally in tokamaks where $T_{e} \approx T_{i} \approx 5 \mathrm{keV}, D^{+}, \rho_{s} \approx \rho_{i} \approx 0.2 \mathrm{~cm}$. Toroidally, the correlation length is expected to be of order $q R \approx 10 \mathrm{~m}$.

These estimates can be used to make a very rough prediction of the characteristics expected from measurements of the magnitude of the phase of a wave reflected from a cutoff layer. Assume that the wave is ordinary, i.e. $\mathbf{E} \| \mathbf{B}$, where the cutoff density is determined by the condition $\omega_{0}=\omega_{p e}$. For long wavelength perturbations one has

$$
\delta n_{e} / n_{e} \approx \delta r / L_{n}
$$

where $\delta r$ is the change in the location of the cutoff as a result of the perturbation $\delta n_{e}$, and $n_{e}$ and $L_{n}$ are evaluated at the cutoff. The phase change outside the plasma, $\delta \Phi$, due to this movement is of order

$$
\delta \Phi \approx 2 \mathrm{k}_{\mathrm{o}} \delta \mathrm{r}
$$

One can estimate the phase change for a drift wave by substituting Eq. (3) and (4) into Eq. (5) to get

$$
\delta \Phi \approx 2 \mathrm{k}_{0} /<\mathrm{k}_{\theta, \mathrm{r}}>2 \mathrm{k}_{\mathrm{o}} \rho_{\mathrm{s}} .
$$

Thus, for probe wavelengths shorter than the fluctuation wavelength, one expects to have phase changes greater than unity.

Similarly, one can estimate the angular deflection, $\delta \psi$, in a test wave traveling approximately in the $r$ direction produced by a poloidal disturbance characterized by $\mathrm{k}_{\theta}$ :

$$
\delta \psi \approx k_{\theta} \delta r
$$

From Eq. (4) for the ordinary wave and Eq. (3) for drift waves one has 


$$
\delta \psi \approx \vartheta(1)
$$

This means that for probe wavelengths short compared to the wavelength of drift wave the surface is always "rough" and reflects or scatters the incident ray through a large angles.

The size of the beam incident on the reflecting region is determined by diffraction. In free space the spot diameter, $s$, is determined by the wavelength and the aperture diameter, $D$, of the window through which the beam is focused over a distance $f$ onto the cutoff layer.

$$
s \approx f\left(\lambda_{o} / D\right)
$$

The changing plasma index will defocus the beam and degrade this estimate, but it provides some guidance about the resolution of the waves in the transverse $(\theta, \phi)$ directions. If $\lambda_{\theta} / 2<\mathrm{s}$, then the phase will measure something about the wave amplitude, but in the opposite limit many different phases will contribute to the reflected wave and the corresponding average phase which arrives outside the plasma will be much smaller. Thus the size of the reflected spot puts an upper limit on the range of $k_{\theta}$ which contribute to the fluctuation spectrum.

\section{Time independent, full wave equations}

Waves with frequencies near the electron plasma and cyclotron frequencies traveling in a cold inhomogeneous magnetized plasma are well approximated by linearizing the MHD fluid equations assuming $\mathrm{m}_{\mathrm{e}} / \mathrm{m}_{\mathrm{i}} \ll<1$, quasineutrality, and considering frequencies which are high compared to collision frequencies

$$
4 \pi \frac{\partial \mathbf{J}}{\partial t}=\omega_{p e}^{2} \mathbf{E}-\omega_{c e} \mathbf{J} \times\left[\frac{\mathbf{B}_{0}}{\mathbf{B}_{\mathbf{o}}}\right]
$$

and Maxwell's equations 


$$
\begin{array}{r}
c^{2} \nabla \times(\nabla \times \mathbf{E})+\frac{\partial^{2} \mathbf{E}}{\partial t^{2}}=-4 \pi \frac{\partial \mathbf{J}}{\partial t} \\
c \nabla \times \mathbf{E}=-\frac{\partial \mathbf{B}}{\partial t}
\end{array}
$$

where $\omega_{p e}=4 \pi n_{e} e^{2 / m_{e}}$ and $\omega_{c e}=e B d m_{e} c$ are the plasma and electron gyrofrequencies, respectively. Here $\mathbf{E}, \mathbf{B}$, and $\mathbf{J}$ are the second order electric and magnetic fields and currents respectively associated with the wave, and $\mathbf{B}_{o}$ is the unperturbed magnetic field. This set of equations describes wave propagation in the vicinity of characteristic cutoff regions determined by the relation of the dominant wave frequency, $\omega_{0}$, to $\omega_{p e}$ and $\omega_{c e}$. If the temporal changes in $\mathbf{E}$ and $\mathbf{J}$ are fast compared to $\mathrm{n}_{\mathrm{e}}$ or $\mathrm{B}_{\mathrm{o}}$ then one can assume a time dependence of the form $e^{i \omega_{o} t}$ and write

$$
\nabla \times(\nabla \times E)-\omega_{0}^{2} / c^{2} \varepsilon: E=0
$$

where

and

$$
\varepsilon=\left(\begin{array}{ccc}
S & -i D & 0 \\
i D & S & 0 \\
0 & 0 & P
\end{array}\right)
$$

Equations (13), (14) and (15) describe the full three dimensional wave propagation of $\mathbf{E}$ alone.

For perturbations typical of a tokamak system and reflectometer geometry, $n_{e}=<n_{e}>+\delta n_{e}(r, \theta)$ and $\mathbf{k}_{o} \cdot \mathbf{B}_{0}=0$, Mazzucato and Nazikian ${ }^{4}$ have given a scattering analysis in the Born approximation for the amplitude of the scattered phase. Here we will concentrate on an "exact" numerical solution of the one dimensional problem with $\delta n_{e}(r)$ and the relationship between the observed phase change external to the plasma to local perturbation in the density. For one dimensional propagation 
perpendicular to a shearless magnetic field ${ }^{5}$ and for variations in $S, D$, and $P$ which depend only on $x$, this set can be reduced to equations which have the form of the time independent Schrodinger wave equation for the ordinary and extraordinary modes of propagation:

Ordinary mode -

$$
\frac{\partial^{2} E_{z}(x)}{\partial x^{2}}+\frac{\omega_{0}^{2}}{c^{2}} \eta_{0}^{2}(x) E_{z}(x)=0
$$

where $E=E_{z}(x) i_{z}, \quad B=B_{o} i_{z}, \eta_{0}^{2}=P=1-\omega_{p e}{ }^{2} / \omega_{0}^{2}$ and the wave becomes evanescent at the boundary defined by $\eta_{\mathrm{o}}{ }^{2}=0$ or $\omega_{\mathrm{o}}{ }^{2}=\omega_{\mathrm{pe}}{ }^{2}$.

Extraordinary mode -

$$
\frac{\partial^{2} E_{y}(x)}{\partial x^{2}}+\frac{\omega_{0}^{2}}{c^{2}} \eta_{x}^{2}(x) E_{y}(x)=0
$$

where $E=E_{x}(x) i_{x}+E_{y}(x) i_{y}, B=B_{0} i_{z}, i_{x} / E_{y}=D / S, \eta_{x}{ }^{2}=\left(S^{2}-D^{2}\right) / S$, and $i$ is the unit vector. The wave becomes evanescent at the boundary defined by $\eta_{\mathrm{x}}{ }^{2}=0$ or $\omega_{\mathrm{o}}^{2} \pm \omega_{\mathrm{ce}} \omega_{\mathrm{o}}-\omega_{\mathrm{pe}}{ }^{2}=0$ (the + and - signs refers to the left and right hand cutoffs respectively, and "right" means that the electric field rotates in the direction of the electron rotation in the magnetic field).

The propagation equations for the ordinary and extraordinary waves are very similar. As in the case of propagation in a uniform media where the substitution $\mathbf{E} \rightarrow \mathbf{E e}^{\mathbf{i k} \cdot \mathbf{x}}$ gives $\nabla \times(\nabla \times \mathbf{E})->-\mathbf{k} \times(\mathbf{k} \times \mathbf{E})$, the differences are in the wave cutoff conditions and the polarization. A CMA diagram showing the ordinary and extraordinary boundary regions $\left(\eta_{x, 0}=0, \eta_{x}>\infty\right)$ versus $\omega_{\mathrm{p}} \mathrm{e}^{2} / \omega_{\mathrm{o}}{ }^{2}$ and $\omega_{\mathrm{c}} / \omega_{\mathrm{o}}$ is shown in Fig. 1. The same boundaries versus frequency and radius for tokamak magnetic field and density distributions $\left[B=B_{0} R /(R+r) ; n_{e}=n_{0}\left(1-r^{2} / a^{2}\right)^{2}\right.$ with TFTR parameters: $B_{0}=5.0 T, R=2.60$ $\mathrm{m}, \mathrm{a}=0.90 \mathrm{~m}$, and $\mathrm{n}_{\mathrm{o}}=5.0 \times 10^{19} \mathrm{~m}^{-3}$ ] are shown in Fig. 2 .

For TFTR parameters one can use a lower frequency at the ordinary mode cutoff or a higher frequency at the right hand extraordinary mode cutoff where $\omega_{0}>\omega_{c e}$. In our example the ordinary mode at $\omega_{d} 2 \pi \approx 50 \mathrm{GHz}$ 
$\left(\lambda_{0} \approx 6 \mathrm{~mm}\right)$ and the extraordinary mode at $\omega_{\mathrm{o}} 2 \pi \approx 140 \mathrm{GHz}\left(\lambda_{\mathrm{o}} \approx 2.14\right.$ $\mathrm{mm})$ are cut off in approximately the same location, $41.6 \mathrm{~cm}$ and $39.7 \mathrm{~cm}$ respectively. However, the higher frequency may have some technical advantages because of its better focusing properties (or smaller launchers), its shorter skin depth, and because a significant region of the plasma is accessible from the large major radius side of the torus.

\section{Particular solutions and approximations}

The solution of Eqs. (16) and (17) have a number of common features. In the propagating region where $\eta^{2}>0$ the solutions are oscillatory. Away from the cutoff location, the field can be estimated by the WKB approximation:

$$
E_{\mathrm{WKB}}(\mathrm{x}) \approx \frac{E_{0}}{\sqrt{\eta(x)}} \sin \left[\Phi_{\mathrm{WKB}}(\mathrm{x})\right] ; \quad \Phi_{\mathrm{WKB}}(\mathrm{x})=\mathrm{k}_{\mathrm{o}} \int_{\mathrm{x}_{\infty}}^{\mathrm{x}} \eta\left(\mathrm{x}^{\prime}\right) \mathrm{dx^{ \prime }}
$$

where the phase has been chosen to be zero at the cutoff to make the field amplitude there zero as well.

In the cutoff region where $\eta^{2}<0$ the solutions are approximately exponentially damped as

$$
E_{E X P} \approx E_{0}^{\prime} e^{-\left(x_{c o}-x\right) / \delta}
$$

where $\mathrm{E}$ varies from its value at cutoff, $\mathrm{E}_{\mathrm{o}}^{\prime}$ (which, in the exact solution, is not zero) in the characteristic distance

$$
\delta_{0, x}=\left|\frac{\omega_{0}^{2}}{c^{2}} \frac{\partial \eta_{0, x}^{2}}{\partial x}\right|_{x=x_{c o}}^{-1 / 3}
$$

For the ordinary and extraordinary modes respectively 


$$
\delta_{0}=\left|\frac{\omega_{0}^{2}}{c^{2}} \frac{1}{L_{n}}\right|_{x=x_{c o}}^{-1 / 3}, \delta_{x}=\left.\left|\frac{\omega_{0}^{2}}{c^{2}}\left[\frac{2}{L_{n}} \pm \frac{\omega_{0} \omega_{c e}}{\omega_{p e}^{2}} \frac{2}{L_{B}}\right]\right|\right|_{x=x_{c 0}} ^{-1 / 3}
$$

where + refers to the right hand cutoff and $\mathrm{L}_{\mathrm{n}, \mathrm{B}}$ are the characteristic scale lengths of the density and magnetic field evaluated at the cutoff. In the example of TFTR given previously these lengths are $\delta_{0}=0.70 \mathrm{~cm}$ and $\delta_{\mathrm{x}}{ }^{+}=$ $0.23 \mathrm{~cm}$, in this example, nearly the same as the free space wavelengths.

When the density profile is linear for $\mathrm{x}<\mathrm{a}$ such that $\eta_{\mathrm{o}}=0$ at $\mathrm{x}=\mathrm{x}_{\mathrm{co}}$ and $\eta_{0}=1$ for $x \geq a$, Eq. (16) can be solved in terms of Airy functions, Ai. ${ }^{6}$ For $\mathrm{a}>\mathrm{x}>\mathrm{x}_{\mathrm{co}}$

$$
E_{2}(x)=E_{0} A i(\zeta) \rightarrow E_{0} /\left[\zeta^{1 / 4} \pi^{1 / 2}\right] \sin \left[\frac{2}{3} \zeta^{3 / 2}+\frac{\pi}{4}\right] \quad \text { when } \zeta>>1
$$

and for $\mathrm{x}<\mathrm{x}_{\mathrm{co}}$

$$
\mathrm{E}_{\mathrm{z}}(\mathrm{x})=\mathrm{E}_{\mathrm{o}} \mathrm{Ai}(-\zeta) \rightarrow 0 \quad \text { when } \zeta \ll<-1
$$

where $\zeta=\left(x-x_{c o}\right) / \delta_{0}$. These solutions have the property that the field maximum occurs at $\zeta=1$ or $\mathrm{x}-\mathrm{x}_{\mathrm{co}}=\delta_{\mathrm{o}}$ and $\mathrm{E}_{\mathrm{max}} / \mathrm{E}_{\mathrm{co}}=\mathrm{Ai}(1) / \mathrm{Ai}(0) \approx 1.508$. When $\zeta \gg 1$, the ratio of the field maximum to the field amplitude for $\mathrm{x}>\mathrm{a}$ is given by

$$
\begin{aligned}
E_{\max }\left(x-x_{c 0}=\delta_{0}\right) / E(x>a) & \approx \sqrt{\pi} A i(1)\left[\left(a-x_{c 0}\right) / \delta_{0}\right]^{1 / 4} \\
& \approx 0.949\left[\left(a-x_{c o}\right) / \delta_{0}\right]^{1 / 4}=0.949\left[\frac{\omega_{0}}{c} L_{n}\right]^{1 / 16} .
\end{aligned}
$$

Finally, since

$$
\frac{2}{3} \zeta^{3 / 2}=\frac{2}{3}\left[\frac{\left(x-x_{c 0}\right)}{\delta_{0}}\right]^{3 / 2}=\frac{\omega_{0}}{c} \int_{x_{c 0}}^{x} \eta_{0} d x
$$


the phase between the incident and reflected waves, as seen well away from the cutoff, is just $\pi / 4$ larger for exact solution than for the geometric cptic (or WKB) solution.

Solutions for density profiles which do not change rapidly on a length scale $\delta$ but are not linear will still have an approximately linear region near the cutoff. Thus, the the exact linear solution provides a model for significant features of the field variation near cutoff, while the WKB solution gives a good approximation to phase and amplitude variation away from cutoff. The estimate given for $\mathrm{E}_{\max } / \mathrm{E}_{\mathrm{co}}$ will be good for any profiles for which $[\delta]_{c o} \ll\left[L_{n}\right]_{c o}$, but $E_{\max } / E_{x>a}$ is not a local quantity and the linear formula cannot be generalized for arbitrary profiles. Nevertheless, for many cases of practical interest one has $a-x_{c o} \approx \vartheta\left(L_{n}\right)$ and the linear formula [Eq. (25)] with $L_{n} \rightarrow\left[L_{n}\right]_{c o}$ provides an estimate of the ordinary mode amplitude.

For long wavelength disturbances the response of the phase measured outside the plasma can be escimated from the change in location of the cutoff. The ordinary mode case has been given in Eqs. (4) and (5). For the right hand extraordinary mode cutoff, $\omega_{0}^{2}-\omega_{c e} \omega_{o}-\omega_{p e}{ }^{2}=0$, tue cutoff position at $\mathrm{x}$ is determined by

$$
\omega_{o}^{2}-\left(e / m_{e} c\right) B(x) \omega_{o}-\left(4 \pi e^{2} / m_{e}\right) n_{e}(x)=0
$$

and the cutoff location, $x^{\prime}$, due to a disturbances $\delta n_{e}$ and $\delta B$ at $x$ is determined by

$$
\omega_{o}^{2}-\left(e / m_{e} c\right)\left[B\left(x^{\prime}\right)+\delta B\right] \omega_{o}-\left(4 \pi e^{2} / m_{e}\right)\left[n_{e}\left(x^{\prime}\right)+\delta n_{e}\right]=0 .
$$

Expanding around $\delta \mathrm{x}=\mathrm{x}-\mathrm{x}^{\prime}$ gives $\mathrm{B}_{\mathrm{o}}\left(\mathrm{x}^{\prime}\right) \approx \mathrm{B}_{\mathrm{o}}(\mathrm{x})+\left(\partial \mathrm{B}_{\mathrm{o}} / \partial \mathrm{x}\right) \delta \mathrm{x}$ and $\mathrm{n}_{\mathrm{e}}\left(\mathrm{x}^{\prime}\right) \approx$ $\mathrm{n}_{\mathrm{e}}(\mathrm{x})+\left(\partial \mathrm{n}_{\mathrm{e}} / \partial \mathrm{x}\right) \delta \mathrm{x}$.

$$
\delta n_{e} / n_{e}+\left(\omega_{c e} \omega_{o} / \omega_{p e}{ }^{2}\right) \delta B / B+\left[\left(\omega_{c e} \omega_{o} / \omega_{p e}{ }^{2}\right) / L_{B}+1 / L_{n}\right] \delta x=0
$$

where $\omega_{c e} \omega_{0} / \omega_{p e}{ }^{2}>1$. The phase change is given by $\delta \Phi=2 k_{0} \delta x$. The phase of the extraordinary mode reflection wave will have some sensitivity to fluctuations in the magnitude of the magnetic field. In tokamaks $\delta B / B<<$ 
$\delta n_{e} / n_{e}$ and the field term is generally negligible. Experimentally, the range of field fluctuations associated with $\mathrm{MHD}$ or incoherent magnetic activity gives $\delta B / B=10^{-4}$ to $10^{-6}$; however there may be special circumstances in which the field term influences the phase.

These estimates do not deal with the question of how long the perturbation wavelength must be nor with what happens when the perturbation wavelength approaches the probe wavelength. In order to investigate this Eys (16) and (17) will be solved numerically. The estimates given above will be found to be valid only when the perturbation wavelength approaches $L_{n}$.

\section{Numerical Solutions of the Time Independent Wave Equation}

A numerical solution of the ordinary mode of Eq. (16) for the previous TFTR example in the vicinity of the cutoff is shown Fig. 3 along with the approximate WKB $\left(x>x_{c o}\right)$ and exponential solutions $\left(x<x_{c o}\right)$. The field is chosen to be unity at cutoff and the WKB amplitude is matched to the exact solution at $\mathrm{x}=\mathrm{a}$. The WKB and exact soiutions are out of phase at the plasma boundary within $0.2 \%$ of $\pi / 4$ and the ratio of the maximum field to the external field is the same as that estimated by the linear density solution within $0.1 \%$. A similar extraordinary mode example, for which the cutoff location is approximately the same, is shown in Fig. 4. No attempt is made here to treat the tunneling problem. It is assumed that the resonance layer is sufficiently far from the cutoff that the wave goes asymptotically to zero beyond the cutoff. Although the details of the extraordinary index variation near cutoff are somewhat different, the phase differs from the WKB estimate of $\pi / 4$ at the boundary by cnly $0.4 \%$ and the ratio of the maximum to the external field is similar to the ordinary case but not well approximated by the linear estimate. These features of the exact and WKB solution are typical for any situation in which $\delta \ll \mathrm{L}_{\mathrm{n}}, \mathrm{a}-\mathrm{x}_{\mathrm{co}}$.

Using the zero order solution found above, the response of the phase of the electric field at $x=a$ to a model perturbation can be calculated. The phase response is related primarily to the spatial period of the 
perturbation and to its location. We choose a perturbation of the form of a wave packet located at $x_{0}$ with a magnitude $\delta n_{0}$, a spatial period, $\Lambda$, extending over a region characterized by a width $\Delta$ :

$$
\delta n_{\mathrm{e}}(\mathrm{x})=\delta \mathrm{n}_{0} \mathrm{e}^{-\left(\mathrm{x}-\mathrm{x}_{0}\right)^{2} / \Delta^{2}} \sin \left[2 \pi\left(\mathrm{x}-\mathrm{x}_{0}\right) / \Lambda\right]
$$

Figs. $5 \mathrm{a}, \mathrm{b}$, and $\mathrm{c}$ show the response of the phase change, $\delta \Phi$, in the ordinary wave of Fig. 3 at the plasma boundary as the perturbation center, $x_{0}$, is moved across the cutoff region. The three examples have $N \lambda_{0}=4.0$, 2.0 , and 1.0 , respectively with $\Delta=2.0 \mathrm{~cm}, \lambda_{0}=0.6 \mathrm{~cm}$, and $\delta \mathrm{n}_{0}=1.0 \times 10^{-3}$ which is small enough that there is no density inversion, that is, $\delta \mathrm{n} / \mathrm{n}<$ $2 \pi \mathrm{L}_{\mathrm{n}} / \Lambda$. Two features may be noted. First, the magnitude of the phase change is much less than the estimate of Eqs. (f) and (5), and, secund, the location of the maximum response moves away from the cutoff location as $\Lambda \rightarrow \lambda_{0}$. The location of maximum response corresponds closely to the wave matching condition $k_{\Lambda} \approx 2 \eta_{0}(x) k_{0}$ in agreement with the scattering formalism of Mazzucato. The WKB solution has approximately the same magnitude as the full wave solution but gives an incorrect location of the maximum response near the cutoff.

When the wavelength of the perturbation is half the probe wavelength, the matching condition is satisfied only at the plasma edge, and the phase response becomes vanishingly small. The change in response and the location of maximum response as the perturbation wavelength approaches the wave matching limit is shown in Fig. 6. The maximum phase change relative to the long wavelength response, $\delta \Phi_{\max } / \delta \Phi_{\Lambda \rightarrow \infty}$, and the location of the maximum response, $x_{\max }-x_{c 0}$, as a function of $\Lambda$ for the ordinary mode described in Figs 3 and 6 are shown. In this case $\delta \Phi_{\Lambda \rightarrow \infty} \approx 0.26$. For the longer wavelentth perturbations the width of the envelope has been correspondingly increased so that the maximum perturbation amplitude is constant.

The wave matching condition can be approximated near cutoff where an expansion for $\lambda_{0} / 2 \Lambda \ll 1$ gives

$$
\mathrm{x}_{\max }-\mathrm{x}_{\mathrm{co}} \approx\left(\lambda_{\mathrm{o}} / 2 \Lambda\right)^{2}\left|\mathrm{~L}_{\mathrm{n}}\right|_{\mathrm{co}}
$$


Similarly, an expansion of the WKB phase for a small amplitude disturbance and $\lambda \sqrt{ }\left|\mathrm{L}_{\mathrm{n}}\right| \ll<$ gives

$$
\delta \Phi_{\max } / \delta \Phi_{\Lambda \rightarrow+\infty} \approx \frac{\pi}{3 \cdot 2^{3 / 2}}\left[\frac{\Lambda}{\left[\mathrm{I}_{-n}\right\}_{c o}}\right]^{1 / 2} \text {. }
$$

The two curves are shown as the solid lines in Fig. 6 .

The extraordinary wave reflection has a very similar character, but the details of the shape of the phase perturbation and the location of the maximum response versus perturbation wavelength change consistent with the shape of $\eta_{x}(x)$ [determined by $n_{e}(x)$ and $B(x)$ ]. For example, for the extraordinary case shown in Fig. 4, a perturbation of the same magnitude and for which $N \lambda_{0}=2$ gives $\delta \Phi_{\max } / \delta \Phi_{\Lambda \rightarrow \infty}=0.070$ which is sirnilar to the ordinary mode case, i.e. $\delta \Phi_{\max } / \delta \Phi_{\Lambda \rightarrow \infty}=0.075$ for the same ratio. As with the ordinary mode, the location of the maximum response follows the matching condition, $\mathrm{k}_{\mathrm{\Lambda}}=2 \mathrm{k} \approx 2 \eta_{\mathrm{x}} \mathrm{k}_{\mathrm{o}}$. Approximately,

$$
x_{\max }-x_{c o} \approx\left(\lambda_{o} / 2 \Lambda\right)^{2} /\left|2 /\left[L_{n}\right]_{c o} \pm\left(\omega_{c} \omega_{o} / \omega_{p}^{2}\right) 2 /\left[L_{B}\right]_{c o}\right|
$$

near cutoff. The shape of the rollover region in Fig. 6, therefore, depends primarily on the details of the index shape near the cutoff.

In summary, long wavelength features in radial density fluctuations in the vicinity of the cutoff dominate the radial phase fluctuation observed external to the plasma. However, the phase can be significantly influenced by waves well away from the cutoff layer whose wavelength is similar to or larger than the wavelength of the probe wave and whose amplitude is sufficiently large.

\section{Correlation Measurements}

Several different correlation measurements are possible with reflectometry. One could reflect from the same cutoff layer with a poloidal or toroidal separation. If the beam spot size [see Eq. (9)] on the cutoff layer, is smaller than the poloidal or toroidal correlation length of the 
fluctuations, one could imagine measuring the correlation between the two reflected phases as a function separation and thereby determine the correlation scale length. Alternatively, the correlation in phase between two reflectometer beams with slightly different wavelengths could be used to estimate the radial correlation length. The latter has been used by several groups to find such radial correlation lengths. ${ }^{8}$ These radial correlation measurements will be examined in this section.

Probes waves made up of different wavelengths corresponding to cutoffs at different positions in the plasma will be modeled. In order to find the spatial coherence of the fluctuating density we consider measuring the coherence of the fluctuating phase. One measures the time history of each fluctuating phase and calculates the normalized cross correlation function for various reflected wave frequencies (corresponding to various spatial separations of their respective cutoff positions). This kind of experiment can be modeled using the same sort of numerical solution to the time independent wave equation considered in Sec. V. The time sampling of the real problem is simulated by making an ensemble average of randomly generated density fluctuation functions $\delta n_{e j}(x)$ each with predetermined spatial coherence properties. This simulation is analogous to a technique originally developed for the turbulence imaging diagnostics a extended for this application. ${ }^{9.10}$ The density perturbation is modeled as a test wave on the interval $(-a, a)$ where

$$
\delta n_{e j}(x) \equiv \delta n_{0} \int_{-a}^{a} h\left(x-x^{\prime}\right) F_{j}\left(x^{\prime}\right) d x^{\prime}
$$

$h(x)$ is a point spread function which determines the spatial correlation properties of $\delta n_{e j}(x)$, and each function $F_{j}(x)$ takes on random values between \pm 1 at each value of $x$ on the interval $(-a, a)$. Each of the $j$ functions, $F_{j}$, is chosen independently, so that both the average of $F_{j}$ 's at a. given value of $x$ or the average of each function $F_{j}$ over $x$ is zero. For a sufficiently large number, $N$, of functions, $F_{j}(x)$, the density autocorrelation function is then 


$$
\begin{aligned}
& <\delta n_{e}\left(x_{1}\right) \delta n_{e}\left(x_{2}\right)>=\lim _{N \rightarrow \infty}\left[\frac{1}{N} \sum_{j=1}^{N} \delta n_{e j}\left(x_{1}\right) \delta n_{e j}\left(x_{2}\right)\right] \\
& <\delta n_{e}\left(x_{1}\right) \delta n_{e}\left(x_{2}\right)>=\frac{\delta n_{0}^{2}}{3} \int_{.}^{.} h\left(x-x_{1}\right) h\left(x-x_{2}\right) d x .
\end{aligned}
$$

The correlation properties of $h$ also specify the $k$-spectrum of the density fluctuations. If the correlation properties are translation invariant, that is, $\delta n_{e j}\left(x_{1}\right) \delta n_{e j}\left(x_{2}\right)>=\rho\left(x_{1}-x_{2}\right)$, then the Fourier transform spectrum is given b y

$$
<\delta n_{e}^{2}(k)>\equiv \int \rho(x) e^{i k x} d x=\frac{\delta n_{o}^{2}}{3}|h(k)|^{2}
$$

If one takes a particular point spread function, $\mathrm{H}$, as

$$
h(x)=\left(\frac{2}{\Delta_{c} \sqrt{\pi}}\right)^{1 / 2} e^{-2 x^{2} / \Delta_{c}^{2}}
$$

then $\quad<\delta n_{e}\left(x_{1}\right) \delta n_{e}\left(x_{2}\right)>\approx\left[\frac{\delta n_{0}^{2}}{3}\right] e^{-\left(x_{1}-x_{2}\right)^{2} / \Delta_{c}^{2}}$

as long as $x_{1}$ and $x_{2}$ are sufficiently far from the ends of the interval. This density autocorrelation function is characterized by a correlation length $\Delta_{c}$. This choice also implies a $\mathrm{k}$-spectrum given from Eq. (37) by

$$
<\delta \mathrm{n}_{\mathrm{e}}^{2}(\mathrm{k})>\approx\left[\frac{\pi \delta \mathrm{n}_{0}^{2}}{3}\right] \mathrm{e}^{-\mathrm{k}^{2} \Delta_{\mathrm{c}}^{2} / 4}
$$

This spectrum falls off rapidly with increasing $\mathrm{k}$ and is roughly consistent with theoretical drift wave models and with microwave scattering measurements of the density fluctuation spectra in tokamak plasmas. ${ }^{11}$

The phase autocorrelation function analogous to the density autocorrelation function is 


$$
<\delta \Phi_{\mathrm{j}}\left(\mathrm{x}_{1}\right) \delta \Phi_{\mathrm{j}}\left(\mathrm{x}_{2}\right)>=\lim _{\mathrm{N} \rightarrow \infty}\left[\frac{1}{\mathrm{~N}} \sum_{\mathrm{i}=1}^{\mathrm{N}} \delta \Phi_{\mathrm{j}}\left(\mathrm{x}_{1}\right) \delta \Phi_{\mathrm{j}}\left(\mathrm{x}_{2}\right)\right]
$$

where $x_{1}$ and $x_{2}$ are taken to be the cutoff locations corresponding to the probe waves $k_{1}$ and $k_{2}$ and the presumption is made that the unperturbed density profile is known with sufficient accuracy that this correspondence can be established.

From the information obtained previously on the response of the phase to a localized test wave, we expect that the phase and density autocorrelation functions will be similar for long wavelength correlations, but somewhat garbled as the coherence length approaches the probe wavelength. Because the model fluctuation function has been constructed to be spatially homogeneous, no information on localization will be found. The questions to be asked are these: What is the relationship between the functions $<\delta n_{e j}\left(x_{1}\right) \delta n_{e j}\left(x_{2}\right)>$ and $<\delta \Phi_{j}\left(x_{1}\right) \delta \Phi_{j}\left(x_{2}\right)>$ ? What is the smallest correlation length which can be resolved by measurements of this type?

Fig. 7 shows the results of a calculation of normalized autocorrelation functions, $\quad<\delta n_{\mathrm{ej}}\left(\mathrm{x}_{1}\right) \delta \mathrm{n}_{\mathrm{e}}\left(\mathrm{x}_{2}\right)>/\left[<\delta \mathrm{n}_{\mathrm{ej}}{ }^{2}\left(\mathrm{x}_{1}>^{1 / 2}<\delta \mathrm{n}_{\mathrm{ej}}{ }^{2}\left(\mathrm{x}_{2}>^{1 / 2}\right] \quad\right.\right.$ an d $\delta \Phi_{\mathrm{j}}\left(\mathrm{x}_{1}\right) \delta \Phi_{\mathrm{j}}\left(\mathrm{x}_{2}\right)>/\left[<\delta \Phi_{\mathrm{j}}{ }^{2}\left(\mathrm{x}_{1}\right\rangle^{1 / 2} \delta \delta p_{\mathrm{j}}{ }^{2}\left(\mathrm{x}_{2}\right\rangle^{1 / 2}\right]$, versus $\mathrm{x}_{1}-\mathrm{x}_{2}$ for an ordinary mode example where $\mathrm{n}_{\mathrm{e}}(\mathrm{x})=1.0 \times 10^{13}\left[1-(\mathrm{x} / \mathrm{a})^{2}\right]^{2}$ and $\lambda_{\mathrm{o}}=1.30$ to $1.55 \mathrm{~cm}$ (which for $\mathrm{a}=90 \mathrm{~cm}$ corresponds to cutoffs at 39.0 and $75.4 \mathrm{~cm}$ ) and correlation lengths $\Delta_{c}=2.0,4.0,8.0$ and $16.0 \mathrm{~cm}$. The constant $\delta \mathrm{n}_{\mathrm{o}}$ has been chosen to make the rms density the same as the maximum of the wave packet used in the example of Fig. 5, that is, $\left\langle\delta \mathrm{n}_{\mathrm{ej}}{ }^{2}(\mathrm{x})\right\rangle^{1 / 2}=0.5 \times 10^{-3}$. The correlation length associated with the phase autocorrelation is always longer than the actual value and is never less than about $8.0 \mathrm{~cm}$. The density autocorrelation is calculated with the same statistical sample as the phase autocorrelation and, because of the limited statistical set $(N=50)$ used in this computation, is an imperfect representation of the parent autocorrelation shown in dotted lines. Nevertheless, the conclusion is that the resolution of correlation lengths less than about four times the mean probing wavelength is not possible. The situation for the extraordinary mode is similar, but, of course, smaller probing wavelengths can be used for a given location in the plasma. The same conclusion would be reached 
by taking the autocorrelation of the WKB solution since no localization of the fluctuations is used in the above calculation. Based on the localization determined from the test wave calculation correlation results showing four to eight times the probe wavelengths would be localized to this degree at the position of the mean cutoff position.

\section{Conclusion}

A time independent, one dimensional, full wave calculation has been used to investigate the interpretation of phase fluctuations measurements in reflectometry and how they relate to localized density fluctuations in a situation typical of tokamak experiments. It is found that density perturbations with wavelengths near the free space wavelength of the probing beam are not resolved. As the wavelength of the perturbation is increased, the location of the region which primarily contributes to the phase fluctuation is given by the location of the scattering matching condition $k_{\Lambda}=2 k=2 \eta(x) k_{o}$. For the ordinary mode this means that when the wavelength of the fluctuations is approximately $\left(\lambda_{o}{ }^{2} L_{n} / 4\right)^{i / 3}$, the maximum phase change occurs one fluctuation wavelength in front of the cutoff. For wavelength fluctuations whose wavelength is approximately $L_{n}$ the phase response is $\delta \Phi \approx 2 \mathrm{k}_{\mathrm{o}} \mathrm{L}_{\mathrm{n}}\left(\delta \mathrm{n}_{\mathrm{e}} / \mathrm{n}_{\mathrm{e}}\right)$, but falls by over a factor of ten at the short wavelength limit given above.

Similarly, density correlation length estimates based on the correlation of phases of probe waves of different frequencies cannot, in this model, produce correlation lengths less than four to eight times the probe beam wavelength. Nevertheless, if one chooses the right hand extraordinary mode cutoff where the probe wavelength can be somewhat smaller for a given cutoff location, one can substantially improve the resolution of the measurement. This means that radial autocorrelation measurements of the order of one centimeter should be possible in a large tokamak. Better spatial resolution is obtained at the highest toroidal field, that is, the highest value of $\omega_{c e}$.

A major limitation on such measurements on tokamaks is associated with an inherent property of drift waves which leads to significant angular 
scattering of the reflected beam caused by poloidally propagating waves. On simple reflectometer systems which use well collimated antenna patterns to minimize the reflection spot size, this can lead rapid amplitude changes in the reflected beam and difficulty in tracking the phase. Phase tracking problems probably related to this phenomena have been encountered in most tokamak reflectometer systems. ${ }^{2}$

\section{Acknowledgement}

The author wishes to thank E. Mazzucato, R. Nazikian, R. Goldston, W. Peebles, G. Hanson, and A. Costley for discussions stimulating the work presented in this paper. This work was supported by U.S. Department of Energy Contract No. DE-AC02-76-CHO-3073. 


\section{Figure Captions}

Fig. 1 A CMA diagram of the cutoffs $(\eta=0)$ and resonances $(\eta-\infty)$ for the cold plasma electron waves. Ext and Ord signify extraordinary and ordinary waves, respectively. $\mathrm{RH}$ and $\mathrm{LH}$ refer to the right and left hand cutoffs and UH to the upper hybrid resonance. Cutoff regions are crosshatched.

Fig. 2 The same cutoffs and resonances shown in Fig. 1 are illustrated in a tokamak field configuration where $B=B_{0} R /(R+r)$ and $n_{e}=n_{0}\left[1-(r / a)^{2}\right]^{2}$ with $\mathrm{a}=90 \mathrm{~cm}, \mathrm{R}_{\mathrm{o}}=260 \mathrm{~cm}, \mathrm{~B}_{\mathrm{o}}=5 \mathrm{~T}, \mathrm{n}_{\mathrm{o}}=5.0 \times 10^{13} \mathrm{~cm}^{-3}$ (typical TFTR parameters). The ordinary mode cutoff at $50 \mathrm{GHz}\left(\lambda_{0}=0.6 \mathrm{~cm}\right)$ and the extraordinary cutoff at $140 \mathrm{GHz}\left(\lambda_{\mathrm{o}}=0.214 \mathrm{~cm}\right)$ are shown.

Fig. 3 The electric field, $E_{z}$ ord, and index, $\eta^{\text {ord }}$, is shown of an ordinary wave with $\lambda_{0}=0.6 \mathrm{~cm}$ reflecting from a cutoff at $x_{c o}=41.6 \mathrm{~cm}$ in the field and density configuration of Fig. 2. The solid line is the exact numerical solution and the dashed line for $x>x_{c o}$ is the WKB solution. The dashed line for $\mathrm{x}<\mathrm{x}_{\mathrm{co}}$ shows the approximate exponential cutoff in the evanescent region.

Fig. 4 The electric field, $E_{z}{ }^{e x t}$, and index, $\eta^{\text {ext}}$, is shown of an extraordinary wave with $\lambda_{\mathrm{o}}=0.214 \mathrm{~cm}$ reflecting from a cutoff at $\mathrm{x}_{\mathrm{co}}=$ $39.7 \mathrm{~cm}$ in the field and density configuration of Fig. 2 .

Fig. 5 The response of the phase, $\delta \Phi$, measured at $x=a$ of the ordinary wave of Fig. 3 to a test perturbation in the density of the form $\delta n_{0} \exp [-(x-$ $\left.\left.\mathrm{x}_{0}\right)^{2} / \Delta^{2}\right] \sin \left[2 \pi\left(\mathrm{x}-\mathrm{x}_{\mathrm{o}}\right) / \Lambda\right]$ with $\Delta=2.0 \mathrm{~cm}$ and $\Lambda / \lambda_{\mathrm{o}}=4.0$ (a), 2.0 (b) and 1.0 (c). The location of the perturbation, $x_{0}$, is varied in the vicinity of the cutoff.

Fig. 6 The maximum response of the phase, $\delta \Phi_{\max }$, normalized to the long wavelength phase response, $\delta \Phi_{\Lambda \rightarrow \infty}$, and the location of the maximum response, $x_{\max }-x_{c o}$, is shown as a function of the perturbation wavelength, $\Lambda$, for the ordinary mode situation of Fig. 5. The solid curve for $x_{\max }-x_{c o}$ 
corresponds to the matching condition $k_{\Lambda}=2 \eta_{0} k_{0}$ and the solid curve for $\delta \Phi_{\max } / \delta \Phi_{\Lambda \rightarrow \infty}$ represents the approximation of Eq. (32).

Fig. 7 The normalized density correlation function, $<\delta n_{e j}\left(x_{1}\right) \delta n_{e j}\left(x_{2} P_{N} \equiv\right.$ $\delta \mathrm{n}_{\mathrm{ej}}\left(\mathrm{x}_{1}\right) \delta \mathrm{n}_{\mathrm{ej}}\left(\mathrm{x}_{2}\right)>/\left[<\delta \mathrm{n}_{\mathrm{ej}}{ }^{2}\left(\mathrm{x}_{1}\right)^{1 / 2} \delta \mathrm{n}_{\mathrm{ej}}{ }^{2}\left(\mathrm{x}_{2}\right)^{1 / 2}\right], \quad$ and phase correlation function, $\delta \Phi_{\mathrm{j}}\left(\mathrm{x}_{1}\right) \delta \Phi_{\mathrm{j}}\left(\mathrm{x}_{2} \mathrm{P}_{\mathrm{N}}=\delta \Phi_{\mathrm{j}}\left(\mathrm{x}_{1}\right) \delta \Phi_{\mathrm{j}}\left(\mathrm{x}_{2}\right)>/\left[\left\langle\delta \Phi_{\mathrm{j}}{ }^{2}\left(\mathrm{x}_{1}\right)^{1 / 2} \delta \Phi_{\mathrm{j}}{ }^{2}\left(\mathrm{x}_{2}\right)^{1 / 2}\right]\right.\right.$, are shown versus the cutoff separation, $x_{1}-x_{2}$, for parent correlation functions (dashed lines) described by correlation lengths $2.0,4.0,8.0$, and $16.0 \mathrm{~cm}$. 


\section{$\underline{\text { Reference }}$}

' H. Bottollier-Curtet and G. Ichtchenko, Rev. Sci. Instrum. 5 8, (1987) p. 539; F. Simonet, Rev. Sci. Instrum. 5 6, (1985) p. 664.

2 W. Horton (1984) Handbook of Plasma Physics, Vol. 2. North Holland Publishing Co., Amsterdam; P. Liewer Nucl. Fusion 2 5, p. 543; A. J. Wootton, B. A. Carerras, H. Matsumoto, K. McGuire, W. A. Peebles, C. P. Ritz, P. W. Terry, S. J. Zweben Phys. Fluids B 2 (1990) p. 2879.

${ }^{3}$ T. Stix (1962) The Theory of Plasma Waves McGraw-Hill, Inc., New York.

- E. Mazzucato and R. Nazikian Plasma Phys. Controlled Fusion 3 3(1991) p. 261.

s Shear couples the two modes and allows transformation of one mode to another. This effect is small in tokamaks, but can become significant in RFPs and other high shear devices. See I. Fidone and G. Granata Nucl. Fusion 1 1, (1971) p. 133 and M. Brambilla and M. Moresco Plasma Phys. Controlled Fusion 29 (1987) p. 381. Relativistic effects can also change the cutoffs somewhat. See D. Batchelor, R. Goldfinger, and H. Weitzner Phys. Fluids 27 (1984) p. 2835.

${ }^{6}$ V. L. Ginzberg (1964) Propagation of Electromagnetic Waves in Plasmas. Pergamon Press, New York. p. 192, 365.

' S. Zweben, C. R. Menyuk, and R. J. Taylor, Phys. Rev. Lett. 4 2(1979) p. 1538.

- P. Cripwell A. E. Costley, and A. Hubbard, Proc.16th European Conf. on Controlled Fusion and Plasma Physics, Venice, Italy, Vol. 13B, (1989) p. 75; E. J. Doyle, T. Lehecka, N. C. Luhmann, Jr., W. A. Peebles, R. Philipona, K. Burrell, R. J. Groebner, H. Matsumoto, T. H. Osborne, and DIII-D Group, Rev. Sci. Instrum. 61 (1990) p. 3016; G. R. Hanson, J. B. Wilgen, E. Anibitarte, J. D. Bell, J. H. Harris, J. L. Dunlap, C. E. Thomas, Rev. Sci. Instrum. 61 (1990) p. 3049.

- R. Nazikian and B. Grek Rev. Sci. Instrum. 61 (1990) p. 2899.

${ }^{10} \mathrm{R}$. Nazikian, private communication.

"E. Mazzucato Phys. Rev. Lett. 36 (1976) p. 792; R. E. Slusher and C. M. Surko Phys. Fluids 23 (1980) p. 472; N. Bretz, R. Nazikian, K. L. Wong Proc.17th European Conf. on Controlled Fusion and Plasma Physics, Amsterdam, Netherlands, Vol. IV, (1990) p. 1544.

${ }^{12}$ Informal communications with A. Costley (JET), E. Mazzucato (TFTR), E. Doyle (DIII), and G. Hanson (ATF). 


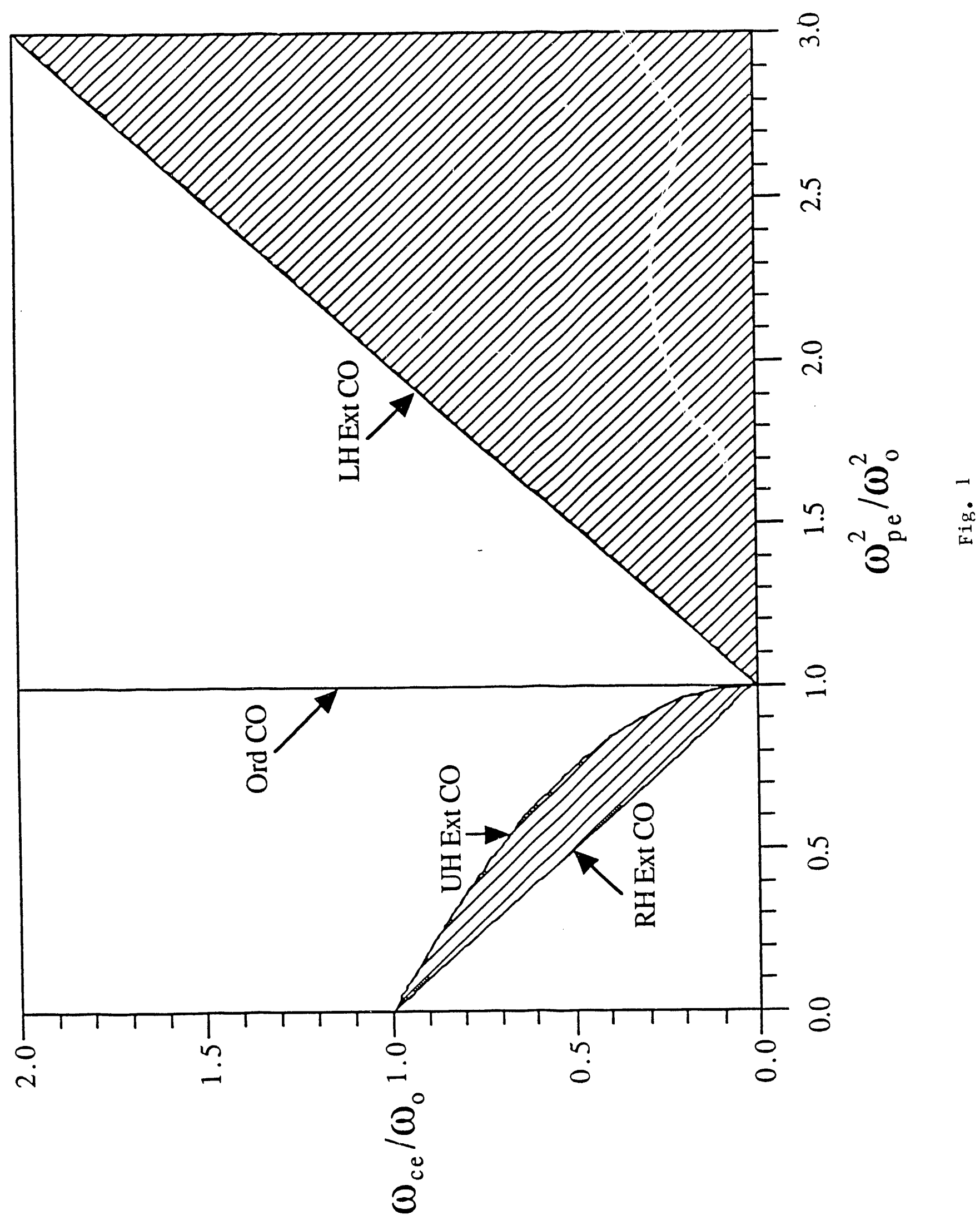




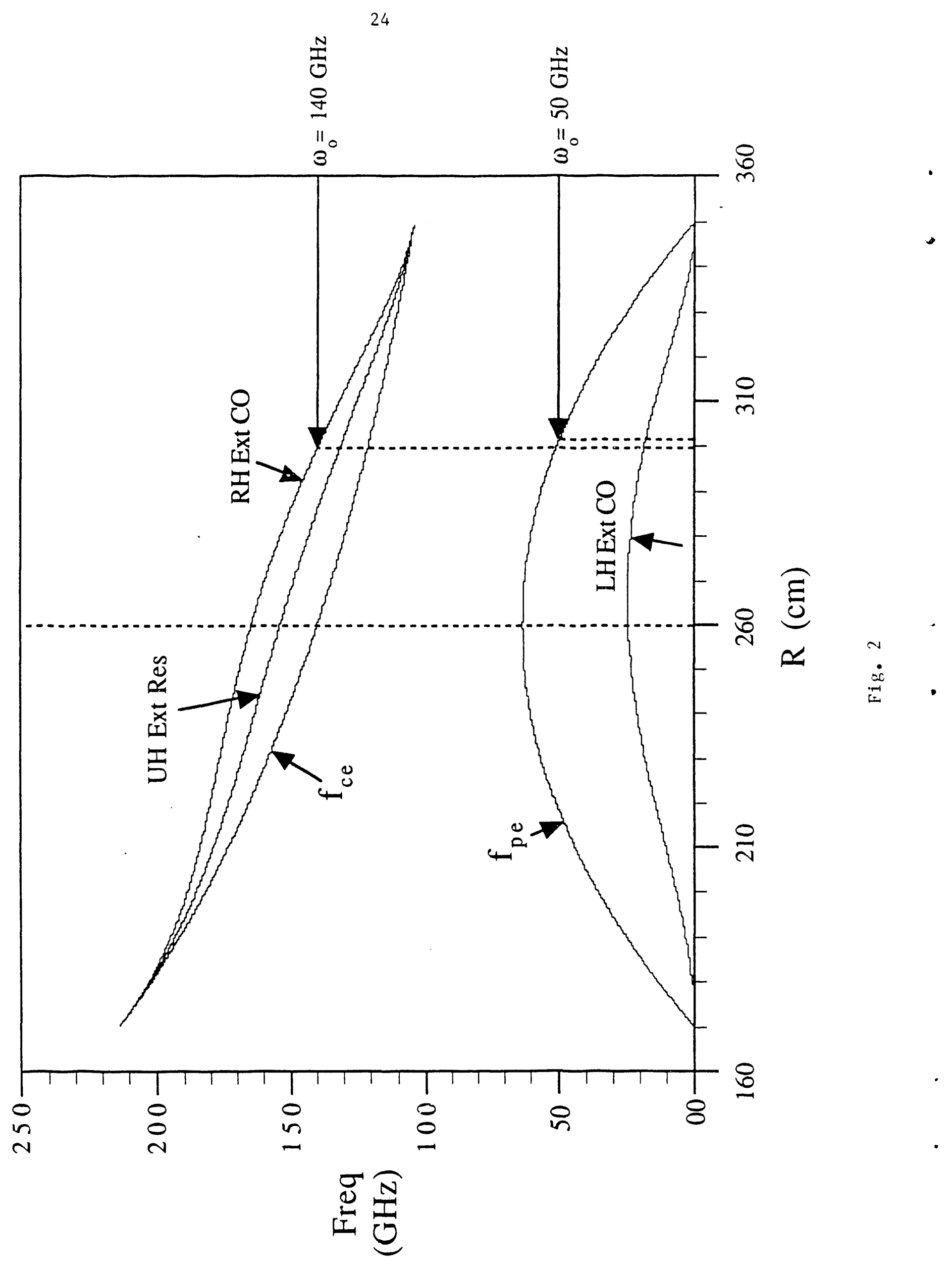




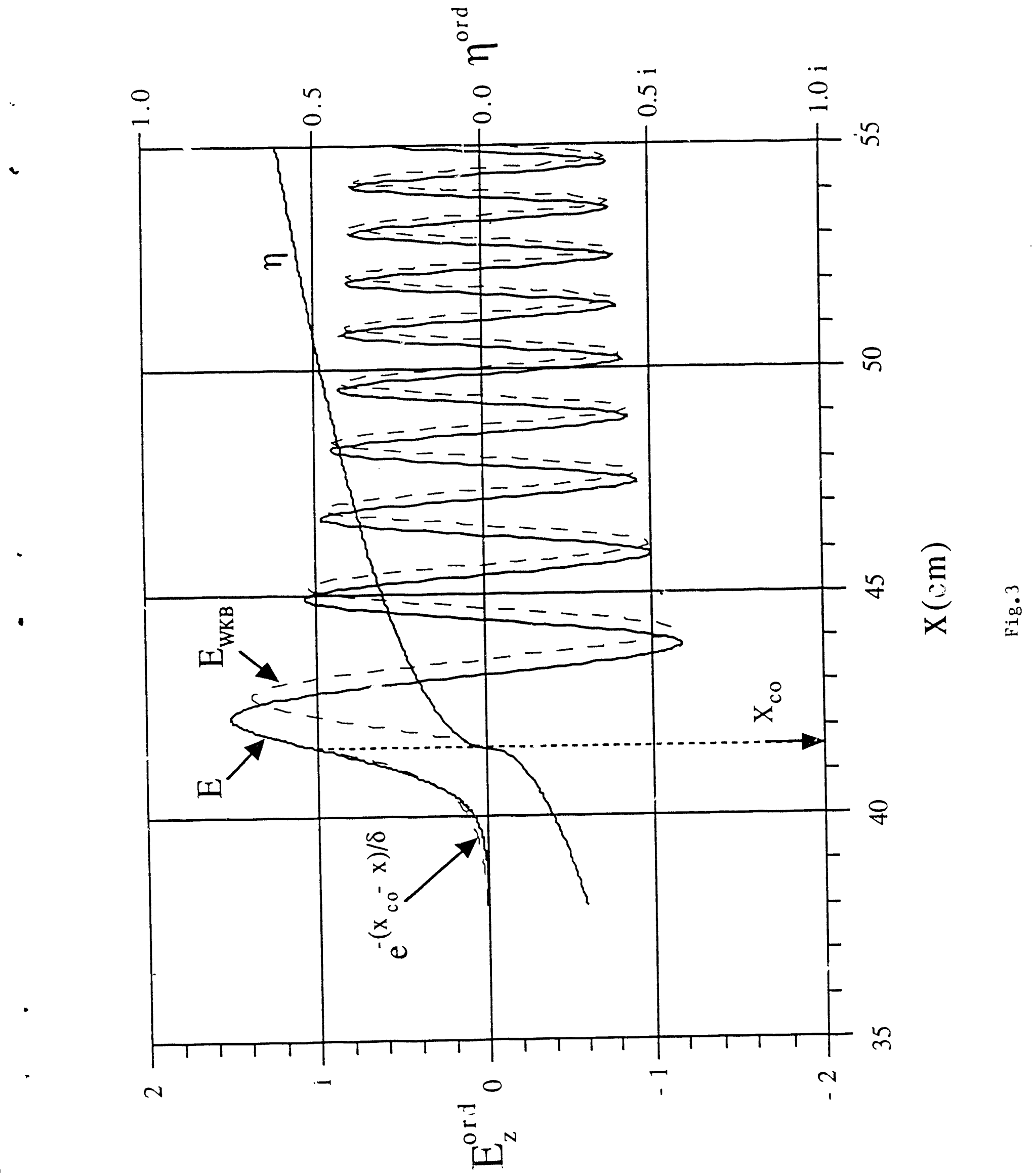




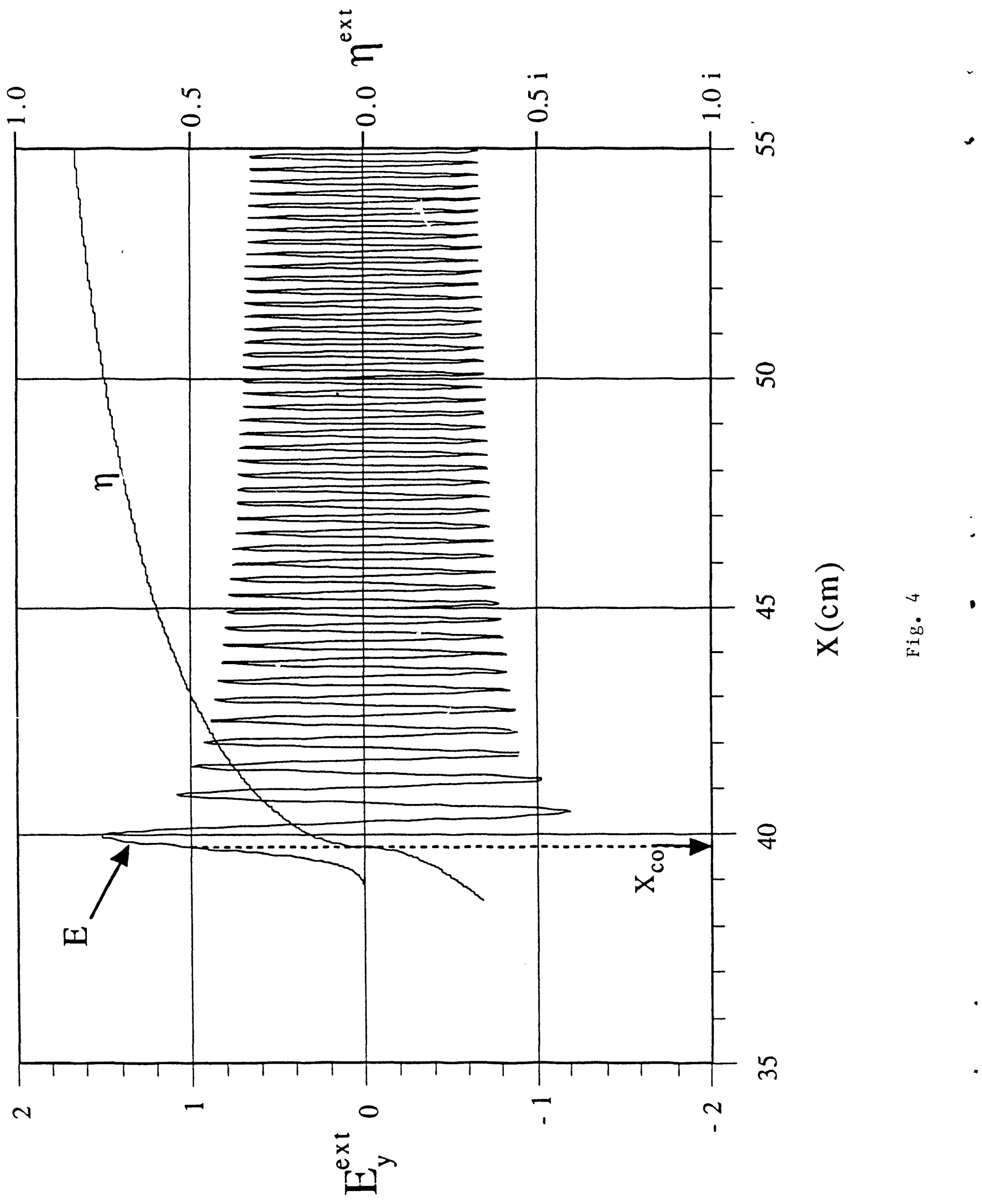




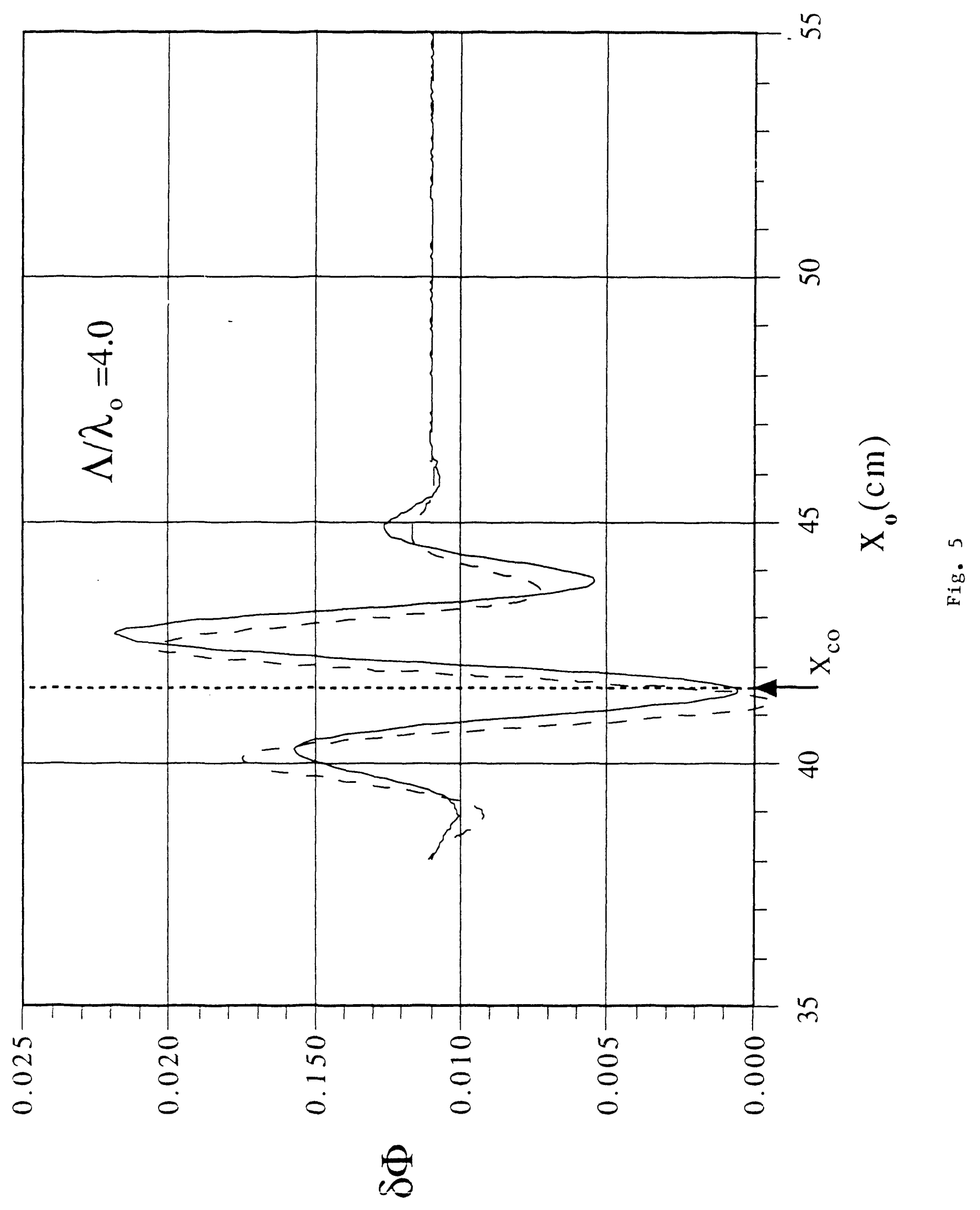




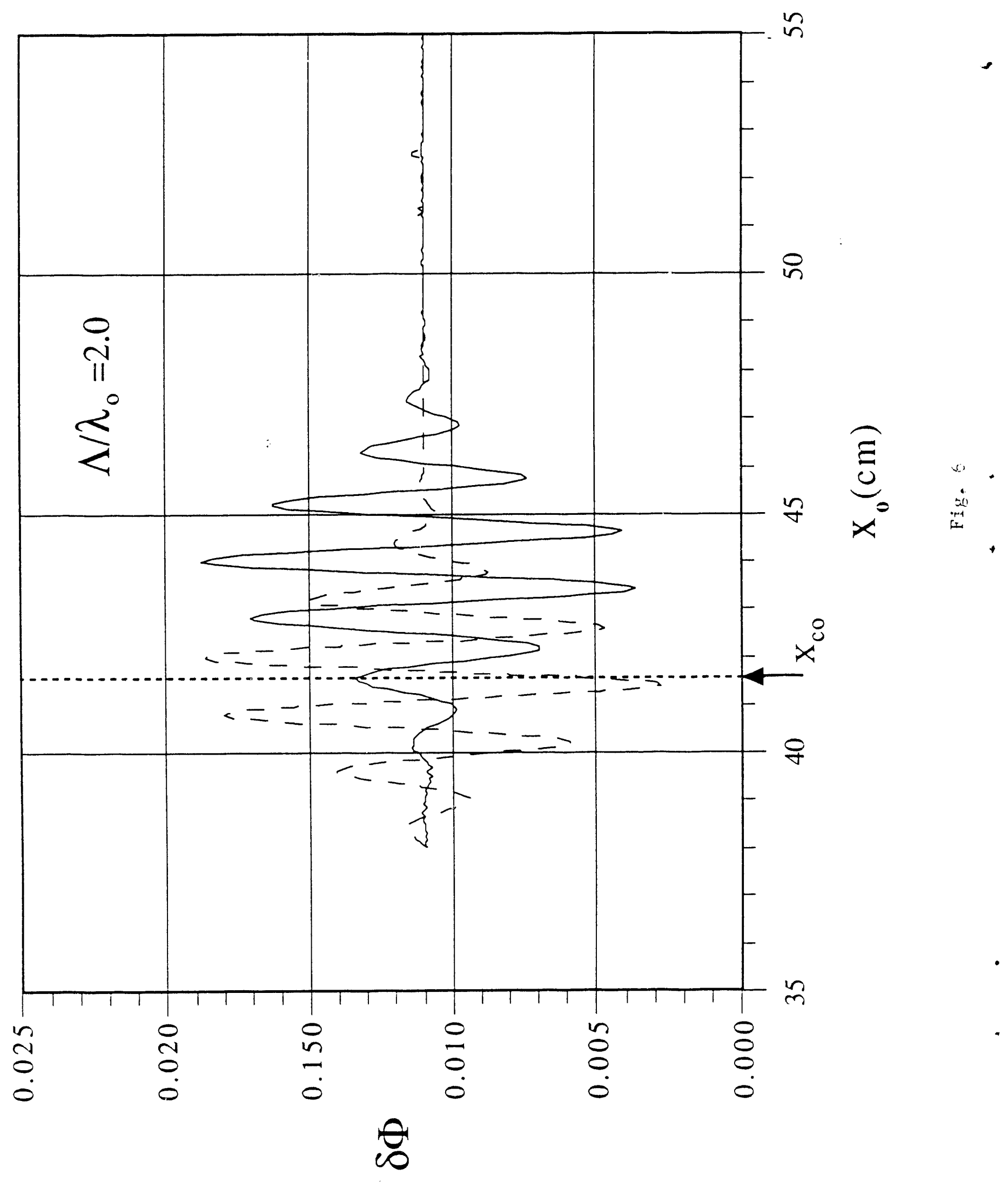




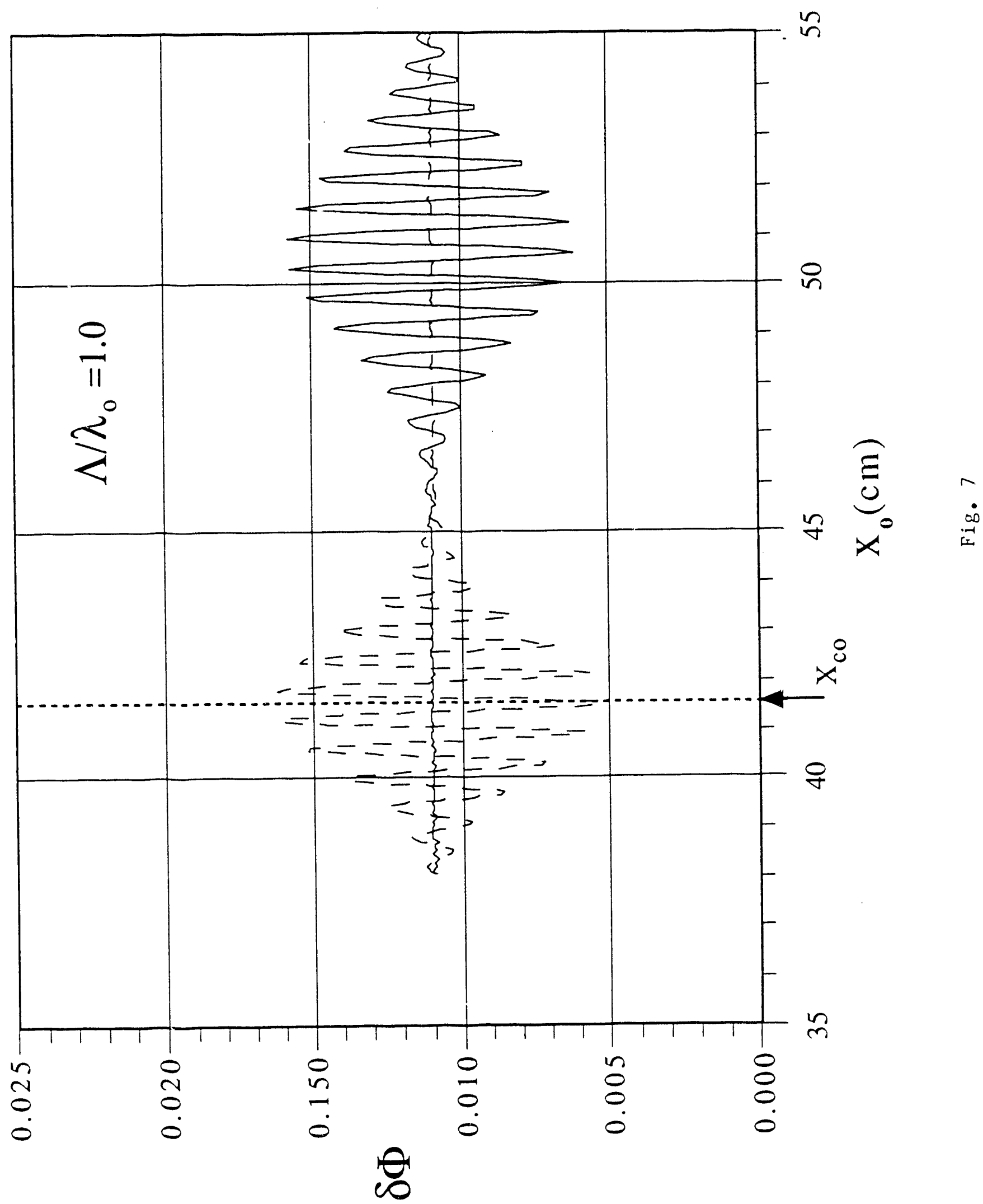




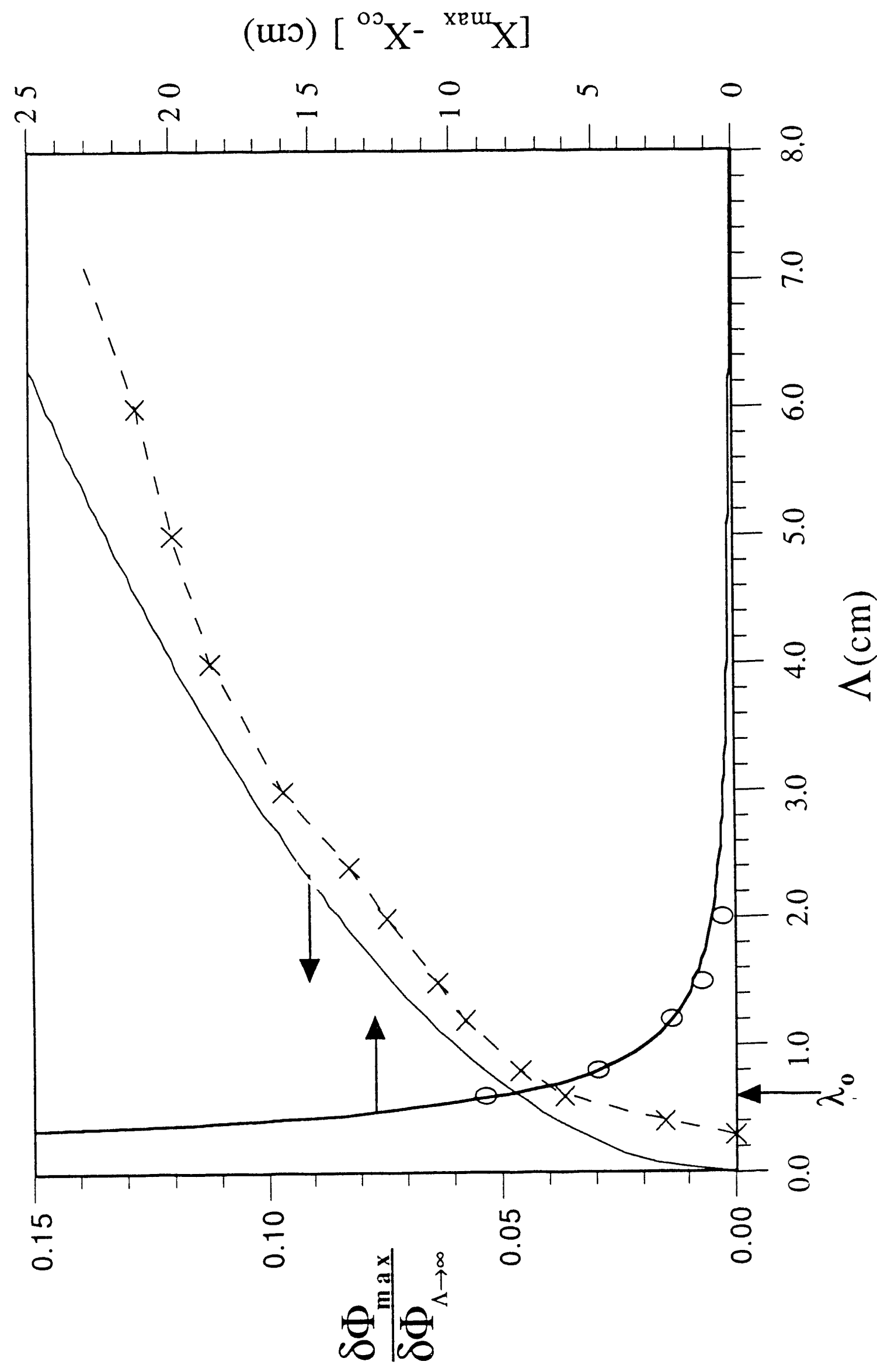




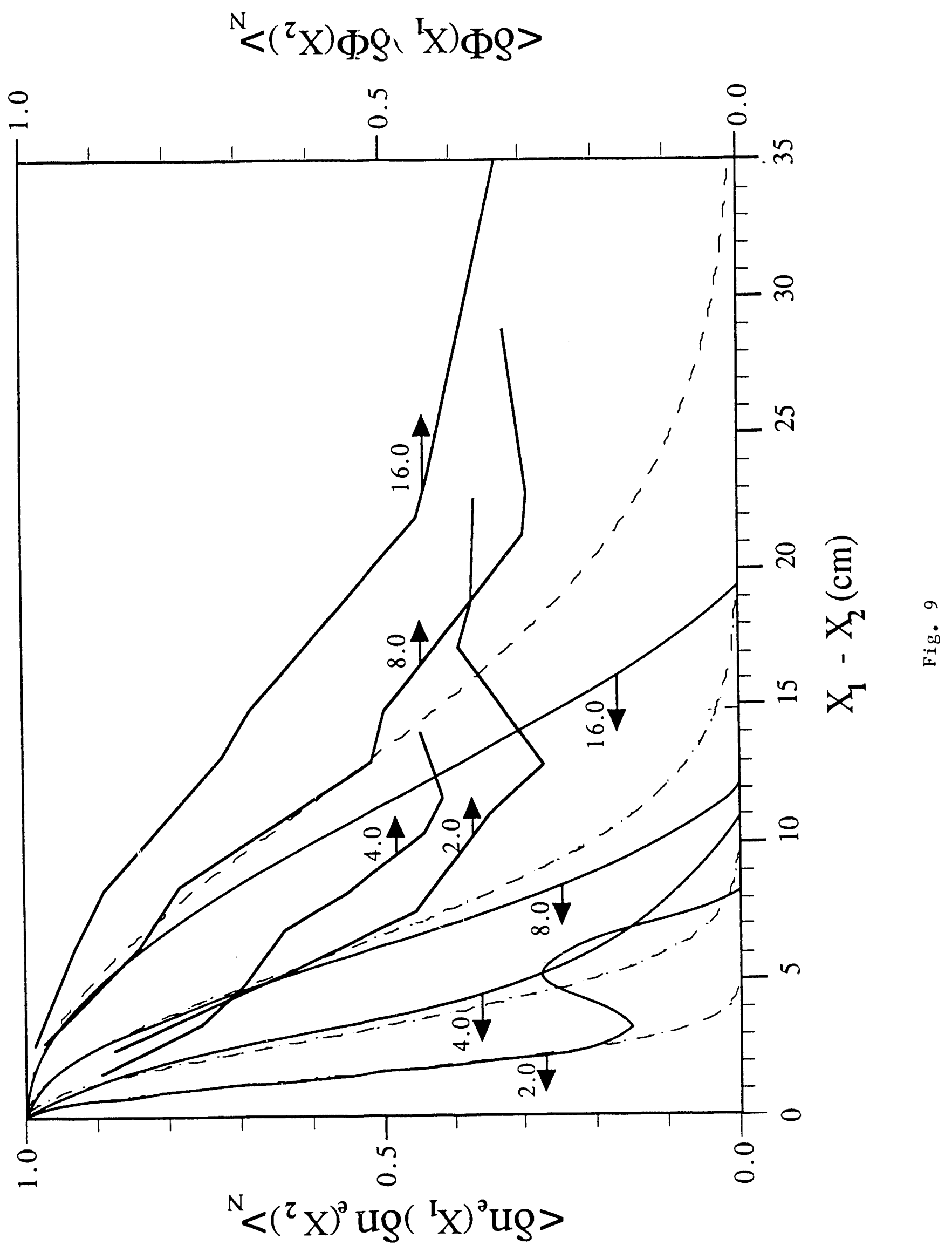


Dr. F. Paoloni, Univ. of Wollongong, AUSTRALIA

Prof. M.H. Brennan, Univ. of Sydnoy, AUSTRALIA

Plasma Research Lab., Australian Nat. Univ., AUSTRALIA

Prof. I.R. Jones, Flinders Univ, AUSTRALIA

Prof. F. Cap, Inst for Theoretical Physics, AUSTRIA

Prof. M. Heindler, Instiut for Theoretische Physik, AUSTRIA

Prot. M. Goossens, Astronomisch InstituUt, BELGIUM

Ecole Royalo Militaire, Lab. de P'my. Plasmas, BELGIUM

Commission-European, DG. XII-Fusion Prog., BELGIUM

Prof. R. Boucique, Rijksuniversiteit Gent, BELGIUM

Dr. P.H. Sakanaka, Instituto Fisica, BRAZIL

Instituto De Pesquisas Espaciais-INPE, BRAZIL

Documents Office, Abomic Enorgy of Canada Lid., CANADA

Dr. M.P. Bectyynski, MPB Technologies, Inc., CANADA

Dr. H.M. Skersgard, Univ. of Saskatchewan, CANADA

Prof. J. Teichmenn, Univ. of Montreal, CANADA

Prof. S.R. Sreenivasan, Univ. of Calgary, CANADA

Prof. T.W. Johnston, INAS-Energie, CANADA

Dr. R. Bolton, Centre canadien de fusion magnstique, CANADA

Dr. C.R. James., Univ. of Aberta, CANADA

Dr. P. Lukac, Komenskeho Universzita. CZECHOSLOVAKIA

The Librarian, Cutham Laborabry, ENGLAND

Library, R61, Rutherford Applewon Laboratory, ENGLAND

Mrs. S.A. Hutchinson, JET Library. ENGLAND

P. Mahonen, Univ. of Helsinkj, FINLAND

C. Moutrot, Lab. de Physique des Milieux lonisés. FRANCE

J. Radet, CEN/CADARACHE - Bat 506, FRANCE

Ms. C. Rinni, Univ. of loannina, GREECE

Dr. T. Mual, Academy Bibliographic Ser., HONG KONG

Preprint Library, Hungarian Academy of Sci., HUNGAPY

Dr. B. Das Gupta, Saha Inst. of Nuclear Physics, INDIA

Dr. P. Kaw, Inst for Plasma Research, INDIA

Dr. P. Rosenau, Isreel Inst. of Tectnology. ISPAEL

Librarian, Intemational Center for Theo Physics. ITALY

Miss C. De Palo, Associazione EURATOM-ENEA, ITALY

Dr. G. Grosso, Istituto di Fisica del Plasma, ITALY

Dr. H. Yamato, Toshiba Res a Devel Center, JAPAN

Prof. I. Kawakami, Atomic Energy Res.Inst., JAPAN

Prof. K. Nishikawa, Hiroshima Univ., JAPAN
Director, Japan Atomic Energy Research inst. JAPAN

Prof. S. Itoh, Kyushu Univ., JAPAN

Data and Planning Conter, Nagoya Univ.. JAPAN

Prot. S. Tanaka, Kyoto Uriv., JAPAN

Library, Kyoto Univ., JAPAN

Prof. N. Inove, Univ. of Tokyo, JAPAN

S. Mori, Technical Advisor, JAERI, JAPAN

O. Mitarai, Kumamoto Inst. of Technology, JAPAN

H. Jeong, Korea Advanced Energy Research Inst., KOREA

Prof. D.I. Choi, The Korea Adv. Inst. of Sa. \& Tech., KOREA

Prof. B.S. Liloy, Univ. of Waikato, NEW ZEALAND

Inst. of Plasma Physics. PEOPLE'S REPUBLIC OF CHINA

Librarian, Inst. of Physics. PEOPLE'S REPUBUC OF CHINA

Library, Tsinghue Univ., PEOPLE'S REPUBLIC OF CHINA

Z. L. S.W. Inst Physics, PEOPLE'S REPUBUC OF CHINA

Prof. J.A.C. Cabral, Instituto Superior Tecnico, PORTUGAL

Dr. O. Potrus, AL I CUZA Univ., ROMANIA

Dr. J. de Villiers. Fusion Surdies, AEC, S. AFRICA

Prof. M.A. Hellberg. Univ. of Natal, S. AFAICA

C.I.E.M.A.T, Fusion Division Library, SPAIN

Dr. L. Stenflo, Univ. of UMEA, SWEDEN

Librey, Royd Inst. of Technology. SWEDEN

Prof. H. Withelmson, Chalmers Univ. of Tech., SWEDEN

Centre Phys. Des Plasmas, Ecole Polytech, SWITEERLAND

Bibliotheok, Inst. Voor Plasma-Fysica. THE NETHERLANDS

M. Durgut, Vico Chairmen, Middle East Tech. Univ., TURKEY

Dr. D.D. Ryutov, Siberian Branch of Academy of Sci., USSR

Dr. G.A. Elieeev, Kurchatov Inst, USSR

Librarien. The Ukr.SSR Acedemy of Sciences, USSR

Dr. LM. Kovrizhnykh, Inst of Genera Physics, USSR

Kemiorschungsaniege GmbH, Zentralbibliothek, W. GERMANY

Bibliothek, Inst. Für Plasmaforschung. W. GERMANY

Prof. K. Schinder, Ruhr-Universitat Bochum, W. GERMANY

Dr. F. Wagner, (ASDEX), Max-Planck-Institut, W. GERMANY

Librerian, Max-Planck-Institut, W. GERMANY

Prof. R.K. Janev, Inst. of Physics, YUGOSLAVIA 

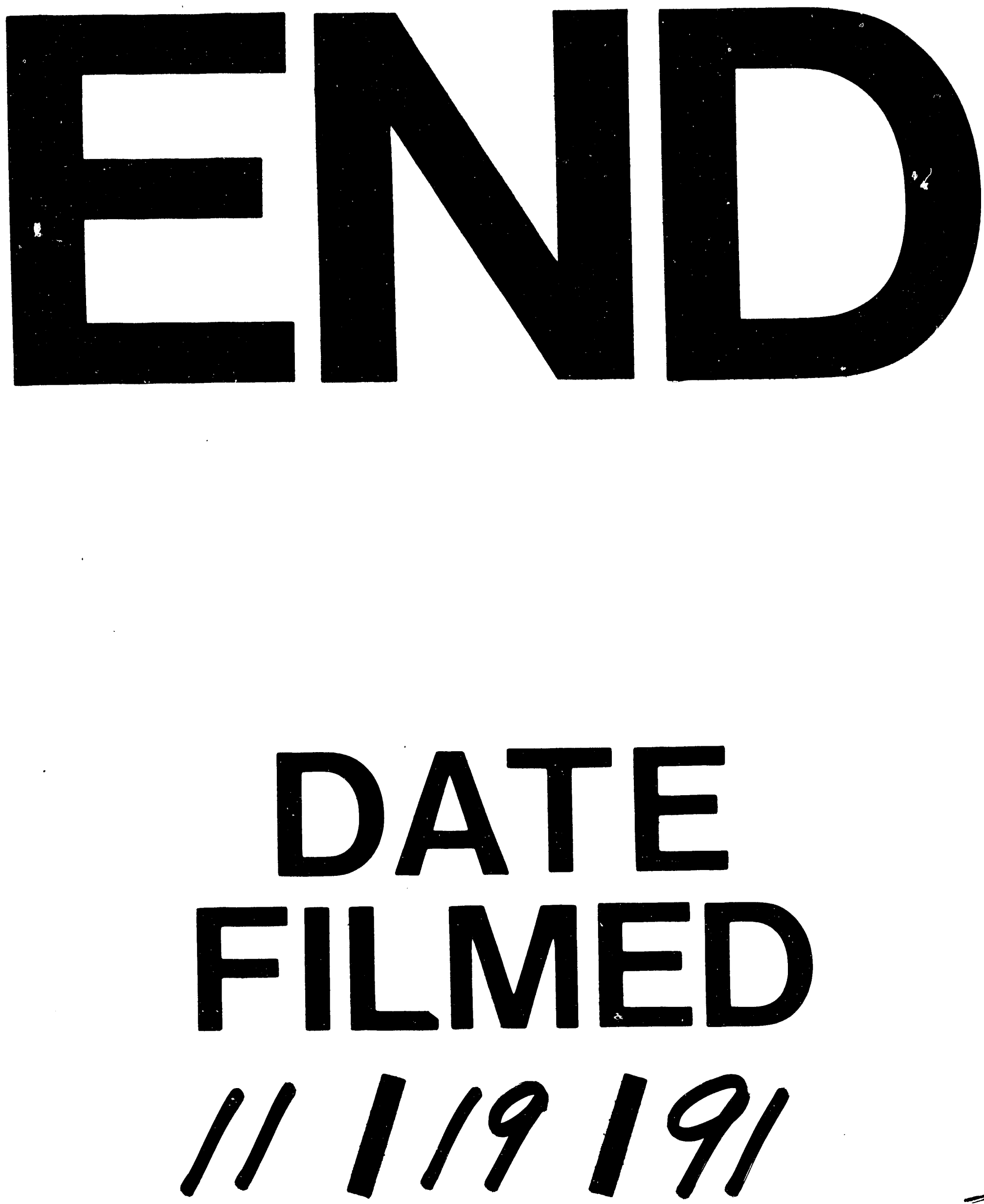

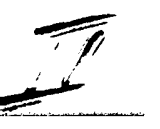


